\title{
IDENTIDAD CULTURAL INDÍGENA EN EL DISCURSO PEDAGÓGICO DE LA HISTORIA. UNA MIRADA AL CURRÍCULUM LATINOAMERICANO*
}

\author{
INDIGENOUS CULTURAL IDENTITY IN THE PEDAGOGICAL DISCOURSE \\ OF HISTORY. A PERSPECTIVE OF THE LATIN AMERICAN CURRICULUM
}

\author{
Omar Turra Díaz ${ }^{* *}$, Mauricio Lagos Pando ${ }^{* * *}$ y Mario Valdés Vera ${ }^{* * * *}$
}

\begin{abstract}
En este artículo se presentan resultados de un estudio que tuvo como objetivo analizar la comprensión de la identidad promovida por la enseñanza histórica, como dimensión formativa escolar, en el contexto de países latinoamericanos que promueven una educación intercultural. El estudio se realizó desde el análisis de contenido, en perspectiva cualitativa, utilizándose como soporte textual documentos curriculares de la asignatura historia escolar de ocho países latinoamericanos. Los resultados investigativos muestran el predominio de un concepto de identidad comprendido como un constructo homogéneo y asociado con la pertenencia social y autoafirmación personal con base en identidades nacionales, no obstante que los Estados participantes del estudio asumieron el reconocimiento de la diversidad cultural indígena y el compromiso de permitir que estos grupos sociales puedan disfrutar de su cultura e historia en el sistema educativo.
\end{abstract}

Palabras claves: Identidad cultural, historia escolar, pueblos indígenas, historia intercultural, currículum.

This article presents the results of a research aimed to analyze the comprehension of the identity promoted by the historical teaching as a school formative dimension, in the context of Latin American countries that encourage intercultural education. This study was developed from a content analysis in a qualitative perspective, using curricular documents from the History subject of eight different Latin American countries as a textual support. Research results show the predominance of a concept of identity understood as a homogeneous construct and associated with the sense of social belonging and self-affirmation based on national identities, however that the participating nations of this research, assume the recognition of the indigenous cultural diversity and agree to allow these social groups enjoying their culture and history within the education system.

Key words: Cultural identity, History subject, indigenous people, intercultural education, and curriculum.

\section{Introducción}

En las últimas décadas los países latinoamericanos han impulsado reformas curriculares con el propósito de actualizar sus itinerarios formativos ante las exigencias, consensos y recomendaciones educativas promovidas desde agencias internacionales (ONU, OCDE, UNESCO, entre otras).

En el caso de la historia como disciplina escolar, la irrupción de nuevos conceptos en las ciencias sociales como diversidad cultural, sociedades multiculturales, interculturalidad, entre otros, son recogidos y reconocidos como características del entramado social actual y antecedentes socioeducativos desde donde se fundan las propuestas formativas en el sector de aprendizaje. Estas nuevas dimensiones hacen complejos los estudios de la historia enseñada, pues sus tradicionales propósitos homogeneizadores en torno a identidades culturales y políticas nacionales, en la actualidad carecen de poder explicativo ante el resurgimiento de las culturas.

Las reformas curriculares en el campo de la historia enseñada en Latinoamérica son impulsadas, además, por la adhesión y reconocimiento que realizan los diversos Estados a la institucionalidad internacional que recoge las demandas de los pueblos originarios (Declaración Universal sobre la Diversidad Cultural de la UNESCO, 2001; Declaración de las Naciones Unidas sobre los Derechos de los Pueblos Indígenas, 2007; Convenio 169 de la OIT sobre Pueblos Indígenas y Tribales, 1989), cuyas normativas promueven, desde un enfoque de derechos educativos y culturales, el acceso a sus historias dentro del sistema educativo, es decir,

\footnotetext{
* Resultados proyecto FONDECYT No 1151233.

** Programa Doctorado en Educación Universidad del Bío-Bío, Universidad Católica de Temuco, Chile. Correo electrónico: oturra@ubiobio.cl

*** Universidad del Bío-Bío, Chillán, Chile. Correo electrónico: mauriciolagospando@gmail.com

*****Universidad de Concepción, Concepción, Chile. Correo electrónico: mariovaldes@udec.cl
} 
que los estudiantes de ascendencia indígena accedan a su patrimonio histórico desde el conocimiento educativo y cultural propio (Turra Díaz et al. 2017).

Es evidente que estos cuerpos normativos interpelan al sistema educativo y a la historia escolar, como uno de sus ámbitos constitutivos, al desarrollar itinerarios formativos abiertos a otras voces y saberes superadores del tradicional discurso pedagógico monocultural y universalista de la historia, para que efectivamente contribuya a la afirmación de identidad social y cultural en las cohortes estudiantiles pertenecientes a pueblos originarios.

En el mismo sentido, desde la investigación en enseñanza de la historia se ha planteado la necesidad de resignificar sus procesos formativos en razón de la multiculturalidad de las sociedades y del estudiantado, y su potencial aporte para una educación intercultural (Castro 2014; Prats et al. 2013; Valls 2011), en la medida que favorece la comprensión y reconocimiento de la diversidad cultural y contribuye a eliminar males sociales, como prejuicios, estereotipos, etnocentrismo y el racismo.

Por su parte, el concepto de identidad comprende una diversidad de entendimientos como cuantas disciplinas científicas participan en la construcción de conocimiento acerca de la temática. Es por ello que, como plantean Ruiz y García de la Huerta (2014), no existe una teoría de la identidad uniforme, pudiendo encontrarse una variedad de denominaciones asociadas a identidad, como subjetivación, autoimagen, autocomprensión, producción de sujetos, etc. Para aportar comprensión al concepto, en este estudio distinguiremos entre identidad personal e identidad colectiva. La identidad personal remite al sujeto, al espacio o esfera del yo, a la dimensión biográfica o subjetiva de la persona. Desde este ámbito la identidad tiene una significación de carácter psicológico, en tanto que refiere a la percepción que cada individuo tiene de sí mismo. Para la psicología, que es la disciplina que estudia este ámbito de la identidad, plantear que el sujeto es el espacio del yo implica concebir al yo como principio de identidad del sujeto, siendo el contexto, los otros/as dimensiones constitutivas de ese yo (Redón 2012). Para la antropología y otras disciplinas sociales la identidad se construye y encuentra sentido en la interacción con otros sujetos, por lo que adquiere relevancia la dimensión social del sujeto en el marco de su pertenencia o adscripción a determinados colectivos. Desde esta dimensión, se ha establecido que en las sociedades modernas las identidades son múltiples, a veces cruzadas y permeadas unas con otras y, por el contrario, la homogeneidad y unidad identitaria es solo realidad "imaginada", como lo plantea Anderson (1993) para el caso de las comunidades e identidades nacionales.

En este estudio se considera la identidad en su vertiente singular y colectiva, pues entendemos que la dimensión intrapersonal e interpersonal se construye y cobra sentido en un contexto sociohistórico que lo explica y condiciona. La complejidad de lo social construye sujetos únicos y diferentes, aun siendo parte de colectivos que comparten códigos culturales comunes (Subercaseaux et al. 2002). Por lo demás, es lo que intencionan los procesos formativos desde el estudio histórico cuando plantean como objetivo que el estudiante conozca quién es (identidad personal) y conozca su comunidad de pertenencia (identidad social). Al respecto, existe consenso en que dotar de identidad a un pueblo, proveerlo de un relato común acerca del pasado y una memoria histórica formadora de sentidos compartidos, es la más antigua y constante función social de la historia (Florescano 2013). Para ello, la memoria histórica se encarga de delimitar el campo de la vida social propia, separándola de la vida de los "otros". En palabras de Villoro, "ninguna actividad intelectual ha logrado mejor que la historia dar conciencia de la propia identidad a una comunidad" (Villoro 1980). De manera generalizada, esta comprensión de identidad fue asumida como política estatal, configurándose un discurso pedagógico de la historia que se construyó a base de un repertorio de imágenes heroicas, que recreaban la trayectoria patria y una representación del pasado social como constitutiva de una "comunidad cultural", derivada y en estrecho vínculo con el mundo europeo-centro-occidental.

Este discurso pedagógico tradicional de la historia es puesto en entredicho por las propuestas renovadoras de la enseñanza histórica, que enfatizan en la potencialidad formativa de esta disciplina escolar en ámbitos como el social, afectivo, político y cognitivo, por medio del desarrollo del pensamiento crítico (Sanz et al. 2017; Plá 2012; Prats et al. 2011).

En línea con estas propuestas renovadoras, para el contexto latinoamericano, Rodríguez Ledesma $(2008,2009)$ plantea la necesidad de renunciar a viejos y consolidados conceptos, nociones y periodizaciones, universalismos y nacionalismos, para dar espacio a la construcción de una historia escolar abierta a las diversas voces y saberes. Sostiene que la diversidad no debe quedarse en lo discursivo en la enseñanza de la historia, sino que debe constituirse 
en una categoría de enriquecimiento cultural en la medida que permita establecer relaciones con otras formas de concebir el pasado, nociones de tiempo, y concepciones de mundo (Rodríguez Ledesma 2009).

Sin embargo es posible advertir, hasta hace poco, la persistencia del enfoque tradicional de la historia escolar en el contexto latinoamericano. De acuerdo con Carretero (2007), en la historia escolar se configura un relato común del pasado, predominando en ella objetivos románticos que guardan una íntima vinculación emotiva con los símbolos y los relatos de identidad nacional, siendo los objetivos de orden cognitivo y de pensamiento crítico relegados a un segundo plano. Se trata de una narrativa que tiene como finalidad educativa prioritaria la proyección "de una imagen positiva, triunfal, progresista" de la historia nacional, para de esta manera formar ideológicamente a las nuevas generaciones como ciudadanos de un Estado (Carretero 2007).

Con lo dicho, puede visualizarse la presencia de propuestas de enseñanza de la historia que configuran versiones o entendimientos de la identidad de manera diferenciada, una vinculada a una identidad común y estatal, y otra que busca relevar identidades culturales asociadas a pueblos originarios, que en muchos casos pugnan con las identidades estatales tradicionales.

Para aportar conocimiento acerca del contenido y orientaciones formativas de la historia escolar, en tiempos de reconocimiento y valoración de la diversidad cultural indígena, en este artículo presentamos resultados de una investigación que tuvo como objetivo analizar la comprensión de la identidad promovida por la enseñanza histórica, como dimensión formativa escolar, en el contexto de países latinoamericanos que promueven una educación intercultural. La interrogante que guio la investigación fue, ¿qué sentido/s formativoidentitarios promueve el discurso pedagógico curricular de la historia escolar en el contexto de sistemas educativos con diversidad cultural indígena? El estudio se realizó desde los currículos oficiales en la asignatura, propuesto por ocho países latinoamericanos.

\section{Metodología}

La investigación se desarrolló desde el análisis de contenido, en perspectiva cualitativa, utilizándose como soporte textual aquellos documentos curriculares oficiales referidos al estudio de la historia en el sistema escolar, específicamente en educación primaria, publicados por los distintos países incluidos en el estudio.

Esta técnica de investigación resulta pertinente en la medida que permite descubrir no solo el contenido manifiesto que se expresa o contiene un documento, sino además aquellos datos y significados que pueden inferirse a partir del texto (Ruiz Olabuénaga 2012). Más allá de los aspectos léxico-gramaticales importa realizar una lectura interpretativa de la información comunicada, resguardando, por cierto, el contexto de comunicación en que se producen.

\section{Criterios de inclusión}

La definición de los Estados latinoamericanos que se consideraron en el estudio se realizó a base de los siguientes criterios de inclusión:

- que en sus datos demográficos reconozcan la presencia de población originaria

- que hayan ratificado el Convenio 169 de la OIT

- que se encuentren impulsando reformas curriculares que promuevan la interculturalidad como aspiración educativa.

Basados en estos criterios se consultaron los siguientes países:

Tabla 1. Porcentaje de población indígena por país y año de ratificación Convenio 169.

\begin{tabular}{lcc}
\hline País & \% población indígena & Año de ratificación \\
\hline Bolivia & 62,2 & 1991 \\
Guatemala & 41 & 1996 \\
Perú & 24 & 1994 \\
México & 15 & 1990 \\
Chile & 11 & 2008 \\
Ecuador & 7 & 1998 \\
Colombia & 3,4 & 1991 \\
Argentina & 2,4 & 2000 \\
\hline
\end{tabular}

Fuente: CEPAL (2014: 163). 


\section{Documentos curriculares consultados}

La información requerida para los fines del estudio se obtuvo de dos tipos de documentos oficiales: aquel que organiza el Currículo Base de Educación Primaria en los diversos Estados y los programas específicos del ámbito de la historia escolar, disciplina que recibe distintas denominaciones según el Estado de que se trate, siendo el más común el de Ciencias Sociales. Según las características educativas específicas se utilizó uno u otro, o ambos. Todos estos documentos se encuentran en portales de los respectivos Ministerios de Educación, desde donde fueron bajados para el estudio.

La Tabla 2 organiza esta información.

\section{Unidades de análisis}

En el estudio, las unidades de análisis refieren a los párrafos de contenido respecto de los que realizamos el proceso analítico e interpretativo. Son unidades o registros extraídos de los documentos, luego de ser individualizados, para posteriormente ser agrupados en un conjunto homogéneo de información de acuerdo con las dimensiones o categorías preestablecidas.

\section{Dimensiones de análisis}

Estos constructos conceptuales surgen de las aportaciones teóricas, razonamientos y procesos inferenciales de los investigadores en relación con el objeto de estudio. En esta perspectiva, las dimensiones o categorías que se levantan tienen un carácter apriorístico y descriptivo, en el sentido que se representan como síntesis o constructos sistematizados de la información recogida, pero con la pretensión de realizar lecturas relacionales entre ellas y aproximaciones teóricas respecto de la problemática en investigación. De esta manera las dimensiones consideradas en el estudio son las siguientes:

- la afirmación identitaria como propósito formativo de la historia escolar

- la identidad colectiva propuesta (nacional/ plurinacional)

Tabla 2. Nombre de la disciplina y documentos curriculares consultados.

\begin{tabular}{|c|c|c|}
\hline País & Nombre de la disciplina & Documento curricular base/consultado \\
\hline Bolivia & Ciencias Sociales & $\begin{array}{l}\text { - Currículo Base del Sistema Educativo Plurinacional. Currículo Subsistema } \\
\text { de Educación Regular. } 2012 . \\
\text { - Educación Primaria Comunitaria Vocacional. Programa de Estudio de } \\
\text { Primero a Sexto Año de Escolaridad. } 2014 .\end{array}$ \\
\hline Guatemala & Ciencias Sociales & $\begin{array}{l}\text { - Currículum Nacional Base, Cuarto Grado, Nivel Primario. } 2007 . \\
\text { - Currículum Nacional Base, Quinto Grado, Nivel Primario. } 2007 .\end{array}$ \\
\hline Perú & Personal Social & $\begin{array}{l}\text { - Diseño Curricular Nacional de Educación Básica Regular. } 2008 . \\
\text { - Modificación del DCN. } 2015\end{array}$ \\
\hline México & Historia & $\begin{array}{l}\text { - Programas de Estudio 2011, Guía para el Maestro. Educación Básica } \\
\text { Primaria, Cuarto grado. }\end{array}$ \\
\hline Chile & $\begin{array}{l}\text { Historia, Geografía y Ciencias } \\
\text { Sociales }\end{array}$ & - Bases Curriculares 2012, Historia, Geografía y Ciencias Sociales. \\
\hline Ecuador & $\begin{array}{l}\text { Entorno natural y social }\left(2^{\circ} \text { y } 3^{\circ}\right. \\
\text { grado) } \\
\text { Estudios Sociales }\left(4^{\circ} \text { a } 10^{\circ} \text { grado }\right)\end{array}$ & $\begin{array}{l}\text { - Actualización y Fortalecimiento Curricular de la Educación General Básica } \\
\text { 2010, Estudios Sociales, } 6^{\circ} \text { Año. }\end{array}$ \\
\hline Colombia & Ciencias Sociales & $\begin{array}{l}\text { - Lineamientos Curriculares Ciencias Sociales. } 2002 . \\
\text { - Estándares Básicos de Competencias en Ciencias Sociales. } 2004 .\end{array}$ \\
\hline Argentina & Ciencias Sociales & $\begin{aligned} \text { - Núcleos de Aprendizajes Prioritarios, } 1^{\circ} \text { Ciclo Educación Primaria, } 1^{\circ}, 2^{\circ} \\
\text { y } 3^{\circ} \text { Años, } 2011 . \\
\text { - Núcleos de Aprendizajes Prioritarios, } 2^{\circ} \text { Ciclo Educación Primaria, } 4^{\circ}, 5^{\circ} \\
\text { y } 6^{\circ} \text { Años, } 2011 .\end{aligned}$ \\
\hline
\end{tabular}

Fuente: Elaboración propia (2016). 
- la presencia/ausencia de saberes históricoseducativos de pueblos originarios en la historia escolar.

\section{Resultados}

La información obtenida en el proceso investigativo se organiza y presenta de acuerdo con las dimensiones arriba identificadas.

\section{La afirmación identitaria como propósito del estudio histórico}

Uno de los propósitos fundamentales y transversales de la enseñanza histórica es la formación identitaria del estudiantado que forma parte del sistema escolar. La búsqueda en este sentido es por determinar el tipo de identidad promovida cuando se declara el propósito de afirmación identitaria (personal, social, nacional, etc.).

En la siguiente Tabla 3 se presentan los párrafos extraídos directamente de las bases o programas curriculares que hacen referencia a esta dimensión:

De acuerdo con los propósitos declarados, se pueden distinguir dos entendimientos o comprensiones respecto de la afirmación identitaria. El primero, y mayoritariamente presente en los documentos curriculares, entiende la identidad como un constructo homogéneo y vinculado con la sociedad o Estado que lo propone, y el segundo refiere al reconocimiento y fortalecimiento de las identidades culturales que concurren al sistema escolar.

Respecto del primer entendimiento, se tiene como claro ejemplo lo que se lee en el programa curricular de Ecuador, el que expone que el aprendizaje de los estudios sociales será útil para que los estudiantes busquen una respuesta respecto de sus interrogantes identitarias, considerando a esta como un constructo único e igualitario para toda la nación ecuatoriana. En el caso de Perú, que también clasificaría dentro de esta comprensión, la asignatura Personal Social busca construir una identidad patria totalizante, y en ninguno de sus apartados menciona el reconocimiento pluricultural, a pesar de que un cuarto de su población pertenece a una etnia originaria (ver Tabla 1). Sin embargo, a diferencia de los otros programas, este hace referencia a que se debe reconocer y valorar las características propias del individuo, lo que podría dar cabida al estudio personal, reflexivo y autónomo que hace cada estudiante de sus orígenes, su entorno y su cultura cercana. Para el caso de México, la identidad también se comprende desde la homogeneidad, y su construcción se orienta a que el estudiante se identifique como parte de una sociedad que posee una única cultura, que se desarrolla en un medio ambiente que es común para todos los mexicanos.

Por su parte, en las bases curriculares chilenas que contienen a la asignatura Historia, Geografía y Ciencias Sociales, la búsqueda desde la historia escolar es por conformar un sentido de identidad y pertenencia social asociada a los valores y características de la sociedad chilena. En ningún momento se consideran las múltiples culturas o identidades étnicas que forman parte del Estado chileno, ni tampoco se hace mención a una enseñanza disciplinar de tipo intercultural. Algo similar ocurre con las bases curriculares de Argentina, ya que de forma explícita señalan que en la asignatura de Ciencias Sociales los estudiantes reconocerán que forman parte de una única sociedad, ya que comparten, de manera igualitaria, ideas, prácticas $\mathrm{y}$ valores.

En el segundo entendimiento de afirmación cultural, que postula la valoración y fortalecimiento de las identidades culturales que concurren a la escuela, se pueden considerar los programas curriculares de Bolivia y Colombia. En el caso de Bolivia, se señala claramente que el estudio de las ciencias sociales comprende una diversidad de identidades, particularmente las lingüísticas, étnicas y de género. Esta declaración curricular apunta directamente a un trabajo formativo desde los primeros años de educación histórica, orientado a la interculturalidad y entrega los fundamentos de un Estado que acepta y promueve su composición de tipo pluricultural. Es un currículo integrador de las distintas manifestaciones culturales, de las distintas tradiciones y dialectos que conforman la heterogeneidad cultural del Estado boliviano.

En el caso del currículo colombiano, si bien no se menciona explícitamente una propuesta intercultural, se evidencia la realidad social pluricultural cuando se propone que los alumnos identifiquen las características propias de su cultura, en el caso de pertenecer a una etnia o pueblo originario, y contrasten sus cualidades con otras que también están presentes en su medio. No se habla de la nación colombiana como una sola comunidad, con características homogéneas, sino que se acepta la variedad respecto de las comunidades y que el 
Tabla 3. Tipo de afirmación identitaria promovida por la enseñanza histórica.

\begin{tabular}{ll}
\hline País & \multicolumn{1}{c}{ Afirmación identitaria } \\
\hline Bolivia & "Ciencias sociales: promueve el reconocimiento y fortalecimiento de las identidades lingüísticas, étnicas, \\
& sociolaboral y de género en equidad social, en ejercicio y exigibilidad de los derechos y deberes, facilitando \\
& que los actores educativos asuman un rol protagónico en la construcción de su propia historia" (Currículo \\
& Base del sistema educativo plurinacional, 2012, p. 53). \\
& "A través de las Ciencias Sociales se promueve el desarrollo de capacidades de localización... reafirmando y \\
& revalorizando la identidad de los pueblos indígenas originarios campesinos, las comunidades afrobolivianas, \\
& comunidades interculturales y movimientos sociales urbano-populares". \\
& (Educación Primaria Comunitaria Vocacional Programa de Estudio de Primero a Sexto año de Escolaridad, \\
& 2014, p. 29) \\
& "El Área de Ciencias Sociales proporciona a las y los estudiantes los elementos necesarios para... que sean \\
& participantes activos, responsables, dotados de referentes y de una memoria histórica con capacidad para \\
& entender y practicar una convivencia solidaria y respetuosa de los y las demás". \\
& (Currículum Nacional Base, Cuarto Grado, Nivel Primario. 2007, p. 134) \\
\hline Guatemala & "El área Personal Social tiene como finalidad contribuir al desarrollo integral del estudiante como persona \\
& y como miembro activo de la sociedad. En este sentido, promueve la construcción de su identidad personal \\
& y social, el fortalecimiento de su autoestima y de la estima hacia los otros, mediante el reconocimiento y \\
& valoración de las características propias... lo que implica que todo docente debe crear condiciones pedagó- \\
& gicas, en el aula y en la escuela, para que cada estudiante logre conocerse y valorarse positivamente, tener \\
& confianza y seguridad en sí mismo, expresar sus sentimientos de pertenencia a un grupo social y cultural...". \\
(Diseño Curricular Nacional de Educación Básica Regular. 2008, p. 205)
\end{tabular}

México

Propósitos del estudio de la historia para la educación primaria: "identifiquen elementos comunes de las sociedades del pasado y del presente para fortalecer su identidad y conocer y cuidar el patrimonio natural y cultural... el reconocimiento de valores universales, la diversidad cultural, el fortalecimiento de su identidad, en valorar el patrimonio natural y cultural e identificar y establecer compromisos con la sociedad que les ha tocado vivir".

(Programas de Estudio 2011, Guía para el Maestro. Educación Básica Primaria, Cuarto grado, p. 142)

Chile "En la educación básica, un objetivo central de esta asignatura (Historia, Geografía y Ciencias Sociales) es que los estudiantes adquieran un sentido de identidad y de pertenencia a la sociedad. Saber quién es, conocer su comunidad y consolidar los lazos con ella son elementos fundamentales para el desarrollo integral de un niño. Ahí radica la base que permite a los alumnos comprender su cultura, apropiarse de ella y participar en su construcción".

(Bases Curriculares 2012, Historia, Geografía y Ciencias Sociales, p. 178)

Ecuador En Estudios Sociales, "el aprendizaje de la Historia se orienta a comprender el pasado como la raíz del presente y como respuesta a los interrogantes sobre nuestra identidad".

(Actualización y Fortalecimiento Curricular de la Educación General Básica 2010, Estudios Sociales, $6^{\circ}$ Año, p. 90)

Colombia Al terminar el tercer grado, el manejo de conocimientos en Ciencias Sociales es "Identifico y describo algunas características socioculturales de comunidades a las que pertenezco y de otras diferentes a las mías [...] Identifico los aportes culturales que mi comunidad y otras diferentes a la mía han hecho a lo que somos hoy". (Estándares Básicos de Competencias en Ciencias Sociales. 2004, p. 30)

Argentina En Ciencias Sociales “durante el primer ciclo de la Educación Primaria, la escuela ofrecerá situaciones de enseñanza que promuevan en los alumnos y alumnas el reconocimiento de ideas, prácticas y valores que permiten vivir juntos y reconocerse como parte de la sociedad argentina".

(Núcleos de Aprendizajes Prioritarios, $1^{\circ}$ Ciclo Educación Primaria, $1^{\circ}, 2^{\circ}$ y $3^{\circ}$ Años, 2011, p. 32)

Fuente: Elaboración propia (2016).

estudiante reconozca que pueden existir expresiones culturales distintas a las propias.

Finalmente, el caso de Guatemala es único y escapa a la categorización que proponemos, porque en los propósitos formativos ni siquiera se hace mención a la afirmación identitaria y la asignatura de Ciencias Sociales solo tiene como objetivo formar un individuo socialmente correcto y que posea habilidades cívicas. Llama la atención esta forma de ver y desarrollar la enseñanza de las Ciencias 
Sociales en un país que, luego de Bolivia, presenta un alto porcentaje de población indígena, como se mostraba anteriormente en la Tabla 1.

\section{La identidad colectiva propuesta (nacional/ plurinacional)}

En la historia escolar, de manera tradicional se ha propuesto una identidad colectiva asociada a la idea de patria o nación, es decir, la adherencia a un colectivo nacional imaginario vinculado a la organización estatal. En tiempos de reconocimiento de las culturas y pueblos originarios, esta pretensión resulta cuestionable a la idea de conformaciones diversas y visibles dentro de la realidad social de los Estados. Veamos qué se propone en los currículos oficiales (Tabla 4).

La información aportada por los currículos oficiales permite distinguir dos propuestas de identidad colectiva en la enseñanza histórica: una aspiración vinculada a la idea de un colectivo nacional y otra que considera las identidades culturales varias a nivel de plurinacionalidad.

En la primera perspectiva, caben las declaraciones curriculares de Perú, México, Chile, Ecuador y Argentina, cuyas propuestas de enseñanza coinciden en una búsqueda por aportar una idea de pertenencia a una comunidad nacional, monolítica y monocultural. En el caso de Perú, se propone que los estudiantes aprendan una historia lineal, de continuidad histórica y sin matices culturales. Algo similar se puede leer en el programa curricular de México, donde se aspira a que el estudiantado se sienta parte de un colectivo amplio como es la humanidad, aunque en lo local su pertenencia se construye a base de una identidad nacional mexicana.

Los planes y programas de Chile promueven la adhesión y pertenencia a la sociedad chilena, mediante el estudio de los componentes que sustentan la identidad nacional, la que, si bien se reconoce como dinámica y cambiante, mantiene su unicidad como categoría identificatoria. En el caso de Ecuador, la identidad es entendida como la formación de un ciudadano que debe conocer los elementos constituyentes de la nación ecuatoriana, en un marco de respeto a la diversidad cultural, pero de fortalecimiento de la identidad nacional. Similar situación es la que se visualiza en el programa de Argentina, donde la enseñanza histórica tiene como uno de sus propósitos centrales aportar a la formación de una identidad nacional, aunque respetuosa de la diversidad cultural.
La segunda perspectiva de identidad colectiva propuesta se desprende de los programas curriculares de Bolivia, Guatemala y Colombia. En el caso de Bolivia, la propuesta es por fortalecer las identidades culturales de las naciones y pueblos, en el contexto de un Estado plurinacional. La enseñanza histórica se visualiza como una instancia educativa que aporta a la transformación de la realidad, que obviamente viene a superar la tradicional propuesta identitaria nacional-monocultural. Por su parte, el programa guatemalteco declara abiertamente que los estudiantes deben comprender que forman parte de una nación pluricultural, multiétnica y multilingüe. Desde esta propuesta curricular, si bien se postula un Estado unitario esta comprensión se realiza desde la diversidad social, geográfica, étnica y cultural.

Finalmente, el caso de la propuesta educativa de Colombia presenta una cierta tensión o tránsito entre la diversidad étnica y cultural presente en el territorio estatal y la idea de identidad nacional. En todo caso, se puede entender que la búsqueda es por integrar la diversidad cultural como un componente característico de la sociedad colombiana.

\section{Presencia/ausencia de saberes histórico- educativos de pueblos originarios en la historia escolar}

Las sociedades originarias desarrollaron/desarrollan formas de organizar, interrogar y comprender el pasado desde la oralidad, proceso en el que las personas transmiten conocimientos del pasado y reproducen la cultura. Aquí, son las palabras las que dan cuenta de una experiencia, las que portan un mensaje o un principio que se desea comunicar, por lo que dependiendo de quién las diga y en qué contexto su enunciación puede estar cargada de sentidos simbólicos.

En el caso de la memoria social, se trata de saberes histórico-educativos que forman parte de un programa formativo que organiza la comprensión del mundo desde donde los sujetos definen lo propio y lo ajeno, y otorgan sentido y proyección a su existencia como grupo cultural.

En consideración a los discursos de reconocimiento de la alteridad indígena y la promoción de sus derechos educativos y culturales, resulta de interés visibilizar cómo la historia escolar incorpora/no incorpora saberes histórico-educativos de pueblos originarios en sus programas formativos, de manera que le permita avanzar hacia una 
Tabla 4. Tipo de identidad colectiva propuesta en la enseñanza histórica.

\begin{tabular}{ll}
\hline País & Identidad colectiva propuesta \\
\hline Bolivia & "Las ciencias sociales no deben servir solo para describir y estudiar la realidad boliviana, sino fundamentalmente \\
& para transformarla, fortaleciendo las identidades culturales de la plurinacionalidad, desarrollando procesos de \\
& autodeterminación y despatriarcalización como parte de la descolonización" (Currículo Base del sistema educativo \\
& plurinacional, 2012, p. 32). \\
& "El área se fundamenta en los saberes y la cosmovisión de las naciones y pueblos, para consolidar la revolución \\
& democrática y cultural del Estado Plurinacional a partir del estudio integral de las temáticas que lo conforman, \\
& reconstituyendo una Bolivia con dignidad, honestidad y transparencia desde el proceso educativo" (Educación \\
& Primaria Comunitaria Vocacional Programa de Estudio de Primero a Sexto año de Escolaridad, 2014, p. 29).
\end{tabular}

Guatemala "El área de ciencias sociales... desarrolla actitudes de identificación y una visión de la Guatemala unitaria y diversa social y geográficamente, que los lleve a ubicarse como parte de una nación pluricultural, multiétnica y multilingüe" (Currículum Nacional Base, Cuarto Grado, Nivel Primario, 2007, p. 134).

Perú El estudiante en este grado $\left(5^{\circ}\right)$ "representa gráficamente hechos de su historia nacional utilizando medidas temporales: cuadros cronológicos y líneas de tiempo [...] reconoce la importancia del Sistema Nacional de Defensa Civil para enfrentar situaciones de riesgo [...] Describe y explica los procesos sociopolíticos ocurridos en la historia del Perú, desde los primeros pobladores hasta la República” (Diseño Curricular Nacional de Educación Básica Regular. 2008, p. 222).

México "Con el estudio de la historia en la educación básica, se pretende que los alumnos: reconozcan que son parte de la historia, con identidad nacional y parte del mundo para valorar y cuidar el patrimonio natural y cultural". (Programas de estudio 2011, $4^{\circ}$ grado, p. 141).

La historia permite hacer del aprendizaje un proceso de construcción permanente, tanto personal como social, mediante el desarrollo y fortalecimiento de los valores para la convivencia democrática, la identidad nacional y el legado histórico de la humanidad.

(Programas de Estudio 2011, Guía para el Maestro. Educación Básica Primaria, Cuarto grado, p. 143)

Chile Desde la Historia "se busca que el alumno se familiarice con su herencia cultural y desarrolle un sentido de pertenencia a la sociedad chilena. Para ello, resulta fundamental estudiar el pasado a fin de reconocer aquellos elementos que sustentan este sentido de pertenencia y entender que la identidad nacional es dinámica y va adquiriendo nuevas formas de acuerdo a las transformaciones sociales y culturales".

(Bases Curriculares 2012, Historia, Geografía y Ciencias Sociales, p. 180)

Ecuador "El contenido de los Estudios Sociales, en general, y de la Cívica, en particular, se dirige al objetivo general de preparar a los jóvenes para el ejercicio de los derechos y deberes ciudadanos, mediante el conocimiento de los elementos de la nación ecuatoriana, de las instituciones del Estado y la comunidad internacional. De manera especial, busca preparar al estudiantado para la participación democrática, el ejercicio de los derechos y el cumplimiento de sus obligaciones, en el marco del respeto a la diversidad y al fortalecimiento de la unidad nacional; promover su identificación con la comunidad nacional ecuatoriana...”.

(Actualización y Fortalecimiento Curricular de la Educación General Básica 2010, Estudios Sociales, $6^{\circ}$ Año, pp. 83-84)

Colombia Al terminar el tercer grado, el estándar en Ciencias Sociales es "Me reconozco como ser social e histórico, miembro de un país con diversas etnias y culturas, con un legado que genera identidad nacional [...] Identifico y describo algunos elementos que permiten reconocerme como miembro de un grupo regional y de una nación (territorio, lenguas, costumbres, símbolos patrios...).

(Estándares Básicos de Competencias en Ciencias Sociales. 2004, p. 30)

Argentina En Ciencias Sociales "durante el período que abarca $4^{\circ}, 5^{\circ}$ y $6^{\circ}$ años de la Educación Primaria, la escuela ofrecerá situaciones de enseñanza que promuevan en los alumnos y alumnas, la construcción de una identidad nacional respetuosa de la diversidad cultural [...] La experiencia de participar y comprender el sentido de diferentes celebraciones y conmemoraciones que evocan acontecimientos relevantes para la escuela, la comunidad, la nación y la humanidad".

(Núcleos de Aprendizajes Prioritarios, $2^{\circ}$ Ciclo Educación Primaria, $4^{\circ}, 5^{\circ}$ y $6^{\circ}$ Años, 2011, p. 46)

Fuente: Elaboración propia (2016). 
enseñanza intercultural. La información aportada por los programas curriculares nos dará luces al respecto (Tabla 5).

De la lectura de los programas curriculares de enseñanza histórica puede desprenderse una perspectiva formativa que considera la presencia de saberes histórico-educativos de culturas originarias como contenidos a enseñar en el sistema escolar. Es el caso de Bolivia, que explícitamente plantea la incorporación de saberes y conocimientos sociocomunitarios en perspectiva de la diversidad cultural que caracteriza al país y a la población escolar, basado en sus propias lógicas intraculturales. A partir del desarrollo intracultural propone el diálogo con otras culturas, lo que sin duda da cuenta de una perspectiva intercultural en la enseñanza de la historia escolar. En el mismo sentido puede leerse el programa curricular de Guatemala cuando propone la utilización de los saberes de la comunidad como medio de aprendizaje y el rescate de la información que portan los ancianos como forma de acceder a este conocimiento y saber educativo.

Una segunda perspectiva considera a las culturas originarias como contenidos a enseñar desde la perspectiva de la otredad o extracultural, como una descripción o representación de un desarrollo histórico objetivado por el discurso historiográfico monocultural, de algunos de los Estados nacionales partícipes del estudio. En esta perspectiva, los pueblos originarios son objeto de un relato histórico en que su protagonismo histórico cobra sentido en su relación con la conformación del Estado nacional. En líneas generales, las propuestas curriculares van al rescate de las sociedades precolombinas, de sus actuaciones en los tiempos coloniales. También se enfatiza en el reconocimiento de su legado y en sus manifestaciones y presencia en la actualidad. Con ciertos matices, estas propuestas están presentes en países como Perú, México, Chile, Ecuador, Colombia y Argentina.

A manera de síntesis, los resultados del análisis de cada una de las dimensiones, y las comprensiones identificadas en cada una de ellas, se pueden resumir en la siguiente Tabla 6.

\section{Discusión}

Un primer ámbito a discutir es que, si bien todos los países considerados en el estudio han suscrito acuerdos nacionales e internacionales, en donde se asume el reconocimiento de la diversidad cultural indígena y el compromiso de permitir que estos grupos sociales puedan disfrutar de su cultura e historia en el sistema educativo, la tendencia mayoritaria es a continuar con una educación monocultural en el área de la historia y ciencias sociales. Esto significa, por una parte, que no existe una coherencia político-educativa entre los acuerdos asumidos por estos países y lo que proponen sus programas de enseñanza de historia escolar $\mathrm{y}$, por otra, la persistencia de un relato histórico anclado en una comprensión occidental del mundo. En este sentido, vale la pena insistir en los planteamientos que promueven una resignificación de la enseñanza de la historia en el contexto del resurgimiento de las culturas y la valoración de su potencial formativo, para avanzar en la comprensión de alteridades culturales y en la eliminación de prejuicios sociales, del etnocentrismo y el racismo. Para ello se hace necesario concebir una enseñanza histórica abierta a diversos conocimientos, saberes y voces, de manera que efectivamente se constituya en una instancia educativa de enriquecimiento cultural. Al respecto, compartimos con Rodríguez Ledesma (2009) en la necesidad de historizar viejos y consolidados conceptos, periodizaciones y universalismos, y avanzar hacia una especie de ecología de saberes, al modo de Souza Santos (2013), que permita entender que la comprensión del mundo, del tiempo y del pasado, es mucho más amplia que la comprensión occidental de estos conceptos.

Otro aspecto a discutir es la comprensión de identidad propuesta por la enseñanza histórica, el que mayoritariamente remite a un entendimiento de la afirmación identitaria como un constructo homogéneo y asociado con la conformación estatal de que se trate. Es decir, la construcción de identidad del alumnado se vincula directamente con sociedades nacionales, promoviéndose una pertenencia social y autoafirmación personal sobre la base de identidades patrias. Desde esta perspectiva, la historia escolar asume la tarea de despejar las diferencias étnicas, lingüísticas y culturales, convirtiéndose el aula escolar en el microespacio donde se anuncia y fragua la pertenencia a la gran familia nacional (Carretero 2007). Es evidente, entonces, la persistencia de un discurso pedagógico tradicional de la historia en la mayoría de los Estados considerados en el estudio, cuestión que dificulta cualquier avance hacia una enseñanza histórica en perspectiva intercultural. En este sentido, la propuesta curricular de Bolivia se presenta como una notable excepción, porque sus 
Tabla 5. Tipos de saberes históricos-educativos de pueblos originarios en la enseñanza histórica.

\begin{tabular}{ll}
\hline País & \multicolumn{1}{c}{ Saberes originarios en la enseñanza de la historia } \\
\hline Bolivia & "La intraculturalidad es la recuperación, revalorización y potenciamiento de las culturas de los pueblos y naciones \\
& que conforman Bolivia para fortalecer y reconstituir sus saberes, conocimientos, identidades, lenguas y modos \\
de vivir, promoviendo la reafirmación de la identidad cultural". & (Currículo Base del sistema educativo plurinacional, 2012, p. 33) \\
& "Las Ciencias Sociales en los procesos educativos, incluyen saberes, conocimientos, valores sociocomunitarios \\
& y derechos ciudadanos que fortalecen la identidad sociocultural de la diversidad demográfica del Estado, pro- \\
& moviendo el respeto, la valoración y el desarrollo de la cultura propia en diálogo con otras culturas". \\
& (Educación Primaria Comunitaria Vocacional Programa de Estudio de Primero a Sexto año de Escolaridad, \\
& 2014, p. 29).
\end{tabular}

Guatemala Dosificación de los Aprendizajes Área de Ciencias Sociales: "Utiliza la curiosidad, la experiencia personal y los saberes de su comunidad como medio de aprendizaje [...] participación en eventos en los que se representan mitos, leyendas y textos cosmogónicos, como medio para registrar el pasado de la comunidad [...] entrevistas a los(as) ancianos(as) y demás personas que, en la comunidad, manejan información del pasado [...] descripción de las características de los saberes filosóficos y culturales de la comunidad [...]".

(Currículum Nacional Base, Cuarto Grado, Nivel Primario, 2007, p. 140)

Dosificación de los Aprendizajes Área de Ciencias Sociales: "Utiliza los saberes y procesos de investigación social como medio de aprendizaje para dar respuestas a interrogantes personales [...] utiliza la observación y el registro de información como medio de aprendizaje de los elementos culturales e históricos [...] descripción de las expresiones culturales que relacionan el pasado de los distintos pueblos de América: monumentos, centros ceremoniales, arquitectura, entre otros". (Currículum Nacional Base, Quinto Grado, Nivel Primario, 2007, p. 141)

Perú Desde el Área Personal Social el estudiante "reconoce la diversidad étnica, lingüística y cultural del Perú y la valora como una gran riqueza de nuestro país".

(Diseño Curricular Nacional de Educación Básica Regular. 2008, p. 222)

Conocerá "las culturas prehispánicas más importantes en el Perú y su organización económica: pesca, ganadería agricultura, el sistema agrícola, uso de los andenes, los camellones, las hoyas, las cochas, los canales y acueductos, la Chaquitaclla, la Raucana y los abonos naturales como técnicas productivas durante esta etapa. -El mundo Incaico: leyendas de origen. Expansión incaica. Economía incaica. El ayllu. La reciprocidad: el ayni, la minka, la mita. Fin del Tahuantinsuyo. Machupicchu, patrimonio de la Humanidad.

(Diseño Curricular Nacional de Educación Básica Regular. 2008, p. 219)

México "Se pretende que los alumnos profundicen en el estudio del pasado de nuestro país, desde el poblamiento de América, hasta la consumación de la Independencia, con el fin de que desarrollen una visión amplia, de las sociedad prehispánicas y virreinales, que les permitan reconocer las raíces multiculturales del México actual". (Programas de Estudio 2011, Guía para el Maestro. Educación Básica Primaria, Cuarto grado, p. 155)

Chile "En segundo básico se familiariza a los alumnos con la diversidad cultural de la sociedad chilena y con algunos de los hitos y procesos que han contribuido a esta diversidad a lo largo de su historia. En primer lugar, se estudian los pueblos indígenas que habitaron el actual territorio nacional en el período precolombino, enfatizando el reconocimiento de su legado en expresiones del patrimonio cultural y su presencia en la actualidad. Luego se abordan los aportes realizados por españoles e indígenas y la importancia del mestizaje en la conformación de nuestra sociedad".

(Bases Curriculares 2012, Historia, Geografía y Ciencias Sociales, p. 184)

Ecuador "El contenido curricular de este año se concentra en una aproximación al conocimiento de las sociedades a través de la relación entre formas de organización social, actividades productivas y relación con el entorno. De este modo, la época aborigen recibe ese nombre porque comprende los milenios en que se desenvolvieron las sociedades aborígenes (que conforme pasaba el tiempo, no podían ser denominadas como "primitivas")". (Actualización y Fortalecimiento Curricular de la Educación General Básica 2010, Estudios Sociales, $6^{\circ}$ Año, p. 90)

Colombia Al terminar el quinto grado, el manejo de conocimientos en Ciencias Sociales es "Identifico, describo y comparo algunas características sociales, políticas, económicas y culturales de las comunidades prehispánicas de Colombia y América. Relaciono estas características con las condiciones del entorno particular de cada cultura. Comparo características de los grupos prehispánicos con las características sociales, políticas, económicas y culturales actuales".

(Estándares Básicos de Competencias en Ciencias Sociales. 2004, p. 32)

\begin{tabular}{ll}
\hline Argentina & En Ciencias Sociales, $4^{\circ}$ en relación con las sociedades a través del tiempo se espera "El conocimiento de las \\
& diferentes formas en que las sociedades indígenas cazadoras-recolectoras y agricultoras se relacionaron con la \\
& naturaleza para resolver sus problemas de supervivencia, distribuyeron los bienes producidos, constituyeron \\
& distintas formas de autoridad y elaboraron distintos sistemas de creencias previo a la llegada de los europeos". \\
& (Núcleos de Aprendizajes Prioritarios, $2^{\circ}$ Ciclo Educación Primaria, $4^{\circ}, 5^{\circ}$ y $6^{\circ}$ Años, 2011, p. 48)
\end{tabular}

Fuente: Elaboración propia (2016). 
Tabla 6. Síntesis de las dimensiones formativas para una enseñanza histórica intercultural consideradas en el estudio.

\begin{tabular}{|c|c|c|c|c|c|c|}
\hline \multirow{2}{*}{$\begin{array}{c}\text { Dimensiones } \\
\\
\text { Comprensiones }\end{array}$} & \multicolumn{2}{|c|}{$\begin{array}{l}\text { Afirmación identitaria como } \\
\text { propósito del estudio histórico }\end{array}$} & \multicolumn{2}{|c|}{ Identidad colectiva propuesta } & \multicolumn{2}{|c|}{$\begin{array}{l}\text { Presencia/ausencia de saberes } \\
\text { histórico-educativos de pueblos } \\
\text { originarios en la enseñanza }\end{array}$} \\
\hline & $\begin{array}{l}\text { Constructo } \\
\text { homogéneo- } \\
\text { cultura nacional }\end{array}$ & $\begin{array}{l}\text { Constructo } \\
\text { heterogéneo- } \\
\text { diversidades } \\
\text { culturales }\end{array}$ & $\begin{array}{c}\text { Identidad } \\
\text { nacional }\end{array}$ & $\begin{array}{c}\text { Identidad } \\
\text { plurinacional }\end{array}$ & $\begin{array}{c}\text { Modelo } \\
\text { extracultural }\end{array}$ & $\begin{array}{l}\text { Modelo } \\
\text { intracultural }\end{array}$ \\
\hline Bolivia & & $\checkmark$ & & $\checkmark$ & & $\checkmark$ \\
\hline Guatemala & $\checkmark$ & & & $\checkmark$ & & $\checkmark$ \\
\hline Perú & $\checkmark$ & & $\checkmark$ & & $\checkmark$ & \\
\hline México & $\checkmark$ & & $\checkmark$ & & $\checkmark$ & \\
\hline Chile & $\checkmark$ & & $\checkmark$ & & $\checkmark$ & \\
\hline Ecuador & $\checkmark$ & & $\checkmark$ & & $\checkmark$ & \\
\hline Colombia & & $\checkmark$ & & $\checkmark$ & $\checkmark$ & \\
\hline Argentina & $\checkmark$ & & $\checkmark$ & & $\checkmark$ & \\
\hline
\end{tabular}

Fuente: Elaboración propia (2017).

propósitos formativos se orientan a fortalecer las identidades culturales de las naciones y pueblos, en el contexto de un Estado que se reconoce como plurinacional y diverso culturalmente, visualizando en esta heterogeneidad una potencialidad y riqueza cultural. Desde este marco de comprensión, claramente, la enseñanza histórica adquiere una impronta intercultural y transformadora, ya que con creces viene a superar el tradicional enfoque identitario nacional-monocultural.

Finalmente, en su generalidad las declaraciones curriculares de reconocimiento de la diversidad cultural indígena se inscriben en los sentidos de un discurso multiculturalista que promueve el reconocimiento de ciertas prácticas culturales, lenguas y sistemas de valores de las sociedades originarias, pero lo hace desde una dimensión extracultural y en perspectiva del otro, que excepcionalmente (Bolivia y Guatemala) se traduce en la incorporación de otras epistemes, otras voces y otros saberes históricoeducativos en la enseñanza de la historia. Por cierto, las propuestas curriculares así caracterizadas no comprometen la preeminencia de los saberes culturales occidentales en el currículo escolar, ni menos los principios vertebradores del tradicional discurso pedagógico de la historia. Desde esta comprensión, la historia escolar dificulta el ejercicio de un pensamiento histórico que construya y favorezca la diferencia y la alteridad en el alumnado, cuestiones centrales si se postula la afirmación identitaria y la construcción de subjetividades interculturales (caso de Chile) como finalidades de la enseñanza histórica (Turra Díaz, 2015).

\section{Conclusiones}

La enseñanza de la historia en el contexto educativo latinoamericano se desarrolla aún desde un discurso universalista y con propósitos formativos de identidad nacional, a pesar de los compromisos de reconocimiento y valoración de las identidades culturales indígenas que promueven los discursos estatales. La persistencia de una comprensión tradicional de la enseñanza histórica conlleva un obstáculo educativo en sociedades pluriculturales como las americanas, en tanto impide a los estudiantes de ascendencia indígena acceder a su patrimonio histórico desde el conocimiento educativo y cultural propio en el sistema escolar. Como ha ocurrido históricamente, la promoción de una afirmación identitaria desde parámetros universalistas y extraculturales, de seguro incuba también en la actualidad procesos de alienación cultural y de identidad en las cohortes estudiantiles provenientes de pueblos originarios.

El reconocimiento de derechos educativos y culturales de los pueblos originarios exige la presencia de sus saberes histórico-educativos como contenidos a enseñar en el sistema escolar. Como en el caso de aquellos Estados (Bolivia y Guatemala) que se declaran plurinacionales y explícitamente plantean la incorporación de saberes y conocimientos de culturas originarias, en perspectiva de la diversidad cultural que caracteriza a su población, se hace necesario avanzar con urgencia en la construcción de una historia escolar intercultural con capacidad para incorporar y dialogar con otras formas de comprender el pasado, de organizar y construir el conocimiento, de estar el mundo. 


\section{Referencias Citadas}

Anderson, B.

1993 Comunidades Imaginadas, Reflexiones sobre el origen y la difusión del nacionalismo. Fondo de Cultura Económica, Buenos Aires.

Carretero, M.

2007 Documentos de identidad. La construcción de la memoria histórica en el mundo global. Paidós, Buenos Aires.

Castro, G.

2014 "La historia nacional cuestionada: interculturalidad para una enseñanza de la historia en clave Latinoamericana". Contextos 32:47-58.

De Souza, B.

2013 Descolonizar el saber, reinventar el poder. LOM Ediciones, Santiago de Chile.

Florescano, E.

2013 La función social de la Historia. Fondo de Cultura Económica, México DF.

\section{ONU}

Declaración de las Naciones Unidas sobre los Derechos de los Pueblos Indígenas. Sesión 61 de la Asamblea General de las Naciones Unidas del 13 de septiembre de 2007 (10 de diciembre de 2007). En https://undocs.org/es/A/RES/61/295 (3 de abril de 2018).

OIT

Convenio sobre pueblos indígenas y tribales, núm. 169. En su $76^{\circ}$ reunión del 27 de junio de 1989 (5 de septiembre de 1991). En http://www.ilo.org/dyn/normlex/es/f?p= NOR MLEXPUB:12100:0::NO:12100:P12100_INSTRUMENT ID:312314:NO (3 de abril de 2018).

Plá, S.

2012 "La enseñanza de la historia como objeto de investigación”. Secuencia, 84: 163-184.

Prats, J.; Santacana, J.; Lima, L.; Acevedo, MC.; Carretero, M.;

Miralles, P.; Arista, V.

2011 Enseñanza y aprendizaje de la historia en educación básica. Secretaría de Educación Pública. Gobierno de México, México.

Prats, J.; Barca, I. y Facal, R. (Organizadores)

2013 Historia e identidades culturales. Braga, Universidade do Minho, España.

Redón, $\mathrm{S}$.

2012 "Escuela e identidad: Un desafío docente para la cohesión social”. Polis 10:447-476.
Rodríguez, $\mathrm{X}$.

2008 Una historia desde y para la interculturalidad. Universidad Pedagógica Nacional, México.

Rodríguez, $\mathrm{X}$.

2009 "Historia y diversidad. El lugar de la otredad en la reconversión del paradigma imperante". Cuadernos, México 1:29-38.

Ruiz, C. y García de la Huerta, M.

2014 Construcción de identidad, creación de sentido. Editorial Universitaria, Santiago.

Ruiz Olabuénaga, J.

2012 Metodología de la investigación cualitativa. Deusto, España.

Sanz, P.; Molero, J.; Rodríguez, D.

2017 La historia en el aula. innovación docente y enseñanza de la historia en la educación secundaria. Editorial Milenio, Lleida.

Subercaseaux, B.; Rojo, G.; Oyarzún, K.; Ruiz, C.; Martínez, J.L.; Wallace, D.; Luongo, G.; Salomone, A.; Tala, P.; Castillo, V.; Baeza, A.

2002 Identidades y sujetos. Para una discusión latinoamericana. Ediciones Facultad de Filosofía y Humanidades. Universidad de Chile, Santiago.

Turra Díaz, O.; Catriquir, D.; Valdés, M.

2017 "La identidad negada: Historia y subalternización cultural desde testimonios escolares mapuche". Cadernos de Pesquisa, 163: 342-356.

Turra Díaz, O.

2015 "Profesorado y saberes histórico-educativos mapuche en la enseñanza de historia". Revista EDUCARE, 19:1-20.

UNESCO

Declaración Universal de la UNESCO sobre la diversidad cultural (2 de noviembre de 2001). En http://portal. unesco.org/es/ev.php-URL_ID $=13179 \& U R L \_D O=D O \_$ TOPIC\&URL_SECTION=201.html (3 de abril de 2018).

Villoro, L.

1980 "El sentido de la historia”. En Historia ¿para qué?, editado por C. Pereyra, pp. 35-52. Editorial Siglo XXI, México.

Valls, R.

2011 "La multiculturalidad en la enseñanza de la Historia y el desajuste entre intenciones educativas y prácticas escolares: los retos del presente y del futuro inmediato". Educar em Revista 42: 73-94. 